\title{
Experimental and Simulation Studies of Thermal Distribution on Modified Connector of Li-Ion Battery for Electric Vehicles Application
}

\author{
Agus Risdiyanto ${ }^{1}$, Umar Khayam², Noviadi A. Rachman ${ }^{1}$, Maulana Arifin ${ }^{1}$ \\ ${ }^{1}$ Research Centre for Electrical Power and Mechatronics, Indonesian Institute of Sciences, Bandung, Indonesia \\ ${ }^{2}$ Department of Electrical Power Engineering, Bandung Institute of Technology, Bandung, Indonesia
}

\begin{tabular}{l} 
Article Info \\
\hline Article history: \\
Received May 9, 2016 \\
Revised Jul 15, 2016 \\
Accepted Jul 30, 2016 \\
\hline
\end{tabular}

Keyword:

Contact resistance Li-ion battery connectors Maximum temperature Silver coating

Solidwork

\begin{abstract}
One of the several failure cases in electric vehicle could be occured at the Lithium-ion (Li-ion) battery connectors when loaded by high current. This failure caused by bad contact of connectors so that the contact resistance increase and lead to high power losses, overheating, and it can even cause a fire hazard. This paper presents a thermal distribution of Li-ion battery connectors on different coating material in relation to the value of contact resistance. There were two test samples of modeled: copper connection without coating and copper connection with silver coating. Each sample was loaded by the DC current of 350A, and temperature at the connection was measured until steady state condition reached and simulated by Solidwork software. The results show that the temperature at the inside contact area was higher than the outside contact area of connection that appears caused by higher of the contact resistance. Both measurement and simulation results have same tendency that copper connection with silver coating having lower contact resistance, lower maximum temperature, and lower losses about 32 $\%$ than copper connection without coating. Silver coating can be considered as other alternative to prevent overheating, high losses, and failure in Li-ion battery connector.
\end{abstract}

Copyright (C) 2016 Institute of Advanced Engineering and Science. All rights reserved.

\section{Corresponding Author:}

Agus Risdiyanto,

Departement of Power Electronic and Electric Machinaries,

Research Centre for Electrical Power and Mechatronics, Indonesian Institute of Sciences,

Komplek LIPI, Jl. Sangkuriang, No. 21/154D, Bandung 40135, Indonesia.

Email: riesdian@gmail.com, agus032@lipi.go.id

\section{INTRODUCTION}

Heat generation has become a major issue in the application of Li-ion battery as a power source to drive electric vehicle (EV). Some researchers have been analyzed and provided to reduce the temperature batery using various technique such as improvisation of cooling systems using phase change materials (PCM) [1], Green's Function technique and natural convection strategy [2], a new kind of coolant and liquid metal [3], and pin-fin heat sinks [4]. Other studies also have analyzed the temperature of Li-ion battery using electro-thermal modeling with the spatial variations of electrode parameter and the reaction heat generated inside battery under different operating conditions [5], and improvement of thermal management system based on differences in cell size and cell packaging system [6]. However, only few paper have discussed the heating battery due to problem in connection system. Among of them were the observing connector warming under vibration environment [7] and improvement of connector material using brass-copper connector configuration with contact pressure setting [8].

Of the many types of connections used in Li-ion battery, overlapping bolted connections are the most commonly used. They are versatile, dependable, simple design and fabrication, easy installation, and 
easy maintenance. Generally, the configuration of overlapping bolted connection in Li-ion battery for electric vehicle application is as shown as Figure 1.

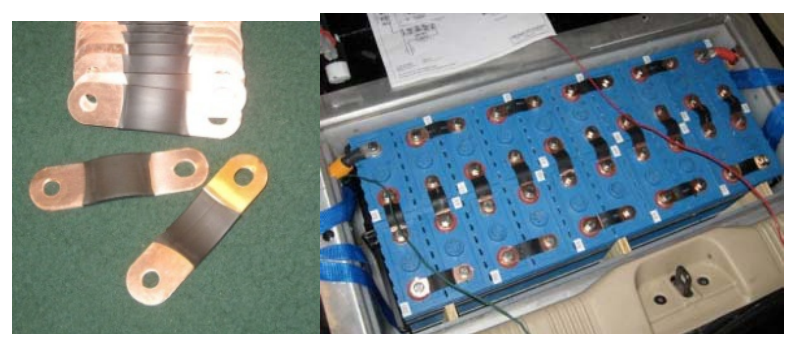

Figure 1. Existing connections with bolted configuration for Li-ion battery

Typically the material existing that use for Li-ion battery connection is copper. This component that has an important role in the transfering of electricity distribution while operating the electric vehicle. The parameters to the reliability of the connection system is a must have integrity, both electrically and mechanically [9]. A good connection system must be mechanically strong and have a small contact resistance. The greater contact resistance on the connection will lead to the greater power losses. Copper connection with high current load can cause the power dissipation. It depends on the value of contact resistance. Maximum temperature permitted for copper connector is not higher than $65^{\circ} \mathrm{C}[10]$. Temperature rise on the connector must be avoided because it can flow into the battery. One of many factors that influenced the residual capacity of the Li-ion battery is temperature of the battery [11], while the Li-ion battery operating temperature for maximum performance, life cycle, and the capacity is between $25-40{ }^{\circ} \mathrm{C}$ [3]. The generation of small voltage drop produces contact temperature that can easily lead to softening or melting of the contact material [12]. The contact spot temperature is related to the voltage drop across the contact interface [13].

In a line with DC electric current load, the power loss is not only determined by resistance of the line conductor, but also determined by value of the contact resistance at each connection and the amount of current flowing in the line [14]. Contact resistance is the main criterion that determines the reliability of the electrical contacts of a connection [15]. Bad electrical contact occurs when only small part of the total surface that having conduction. Area of the actual contact is less than area of expected contact due to constriction. Because the constriction of contact surface, the current density distribution becomes greater and it's become a heating source of a connection (contact spot). The constriction of the contact area can be shown in Figure 2.

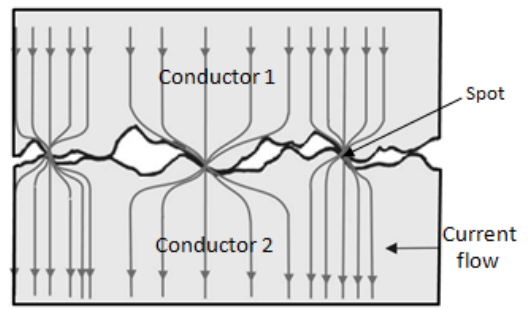

(a)

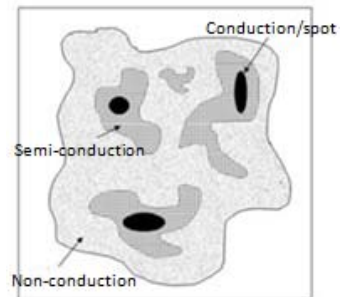

(b)

Figure 2. Current distribution and constriction of contact surface (spot), (a) side view, and (b) top view

In a practical electrical connection, the total area of electrical contact must be made as large as practicable to minimize contact resistance. In contrast, loss of true contact area leads to contact degradation. Resistance arising in the constriction area called constriction resistance and the value depends on the material characteristics such as surface roughness, hardness and resistivity [16]. The optimization of the connections design supposed to determine the value of contact dimension such that the maximum temperature in the contact region remains lower than the acceptable limiting value allowed by standards [17]. Stable and minimum contact resistance of connections will reduce the need for maintenance, decrease overall downtime of equipment, low maintenance costs and greatly reduce the risk of catastrophic failures [18]. 
This paper aims to observe the thermal distribution and efficiency due to losses in the connector of Li-ion batteries for electric vehicle applications using two different sample treatments. There were two test samples of modeled: copper connection without coating and copper connection with silver coating. Those samples were similar to the sample in previous paper but its different in current type [19] due to different application. The experiment was conducted by conventional measurement to compare and analize the results of two samples. Then the simulation was also conducted using Solidwork software to predict the temperature of battery when the testing facility is not available.

\section{EXPERIMENTAL AND SIMULATION SETUP}

\subsection{Experimental Setup}

In many experiments, low resistance measurements are subject to many of the same sources of error as low voltage measurements including offset voltages due to thermoelectric EMFs. For eliminating the termoelectric EMFs, measurement must include different current polarity (reverse-current method).

The models using two samples of bolted copper connection: copper connection without coating and copper connection with silver coating. Silver can be considered for use as a coating material. It has high conductivity, corrosion resistance, and is more economical. Coating thickness usually varies between 0.1 - 30 $\mu \mathrm{m}$ and occasionally up to $100 \mu \mathrm{m}$ depending on the characteristics of the metal material, the operating conditions, as well as other functions that are more specific [16]. In measurement of connector temperature, the sample dimension refers to the Indonesian National Standards (SNI PUIL 2000) with a current capacity of 350A. Current load testing was determined based on the specifications of BLDC motors with a nominal current of 350 A which was used as a main driver of electric vehicle [20]. Contact pressure on each sample performed at $12 \mathrm{MPa}$ [19]. While in measurement of contact resistance of connections performed by 4-wires method, and the amount of current supplied $\left(I_{d c}\right)$ is 2 A. The samples and the methods are as show as Figure 3.

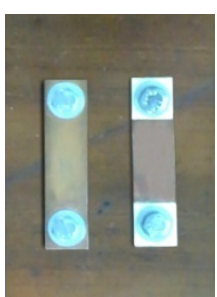

(a)

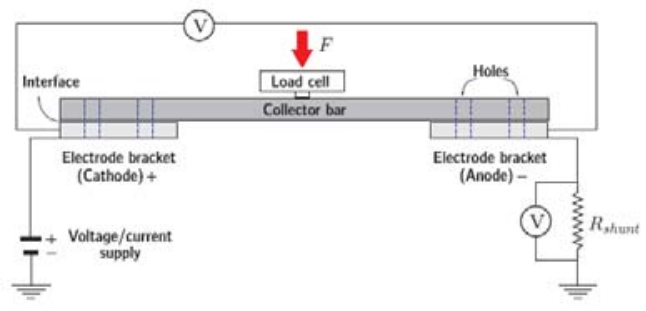

(b)

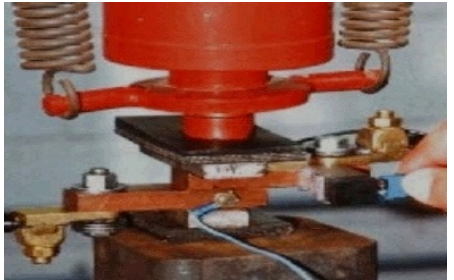

(c)

Figure 3. Contact resistance measurement of connection, (a) Modified samples, (b) Schematic diagram, and (c) Image setup of measurement

Furthermore, to determine the contact resistance $\left(R_{c}\right)$, it was done by calculation, using the following equation [21]:

$$
R_{c}=\frac{\left|V_{f}\right|+\left|V_{r}\right|}{\left|I_{f}\right|+\left|I_{r}\right|}
$$

where, $V_{f}$ is forward voltage drop (volt), $V_{r}$ is reverse voltage drop (volt), $I_{f}$ is forward current (ampere), and $I_{r}$ is reverse current (ampere).

\subsection{Simulation Setup}

Thermal flow simulations enable to predict heat transfer simultaneously on solid material. The phenomenon of anisotropic heat conductivity in solid material is described by the following equation :

$$
\frac{\partial \rho e}{\partial t}=\frac{\partial}{\partial x_{i}}\left(\lambda_{i} \frac{\partial T}{\partial x_{i}}\right)+Q_{H}
$$


where $e$ is the specific internal energy, $e=c \cdot T, c$ is specific heat, $Q_{H}$ is specific heat release (or absorption) per unit volume, and $\lambda_{\mathrm{i}}$ are the eigen values of the thermal conductivity tensor. It is supposed that the heat conductivity tensor is diagonal in the considered coordinate system, then for isotropic medium $\lambda_{1}=\lambda_{2}=\lambda_{3}=\lambda$.

If a solid consists of several solids attached to each other, then the thermal contact resistances between them (on their contact surfaces), specified in the Engineering database in the form of contact resistance $\left(r_{c}\right)$ can be taken into account when calculating the heat conduction in solids. As a result, a solid temperature step appears on the contact surfaces. In presence of the electric current, the corresponding specific Joule heat $Q_{J}\left(\mathrm{~W} / \mathrm{m}^{3}\right)$ is released and included in $Q_{H}$ of heat transfer equation (2). In the case of isotropic material $Q_{J}$ is:

$$
Q_{j}=i^{2} \cdot r
$$

where $r$ is the solids electrical resistivity $(\Omega \cdot \mathrm{m})$, it can be temperature-dependent and $i$ is the electric current density $\left(\mathrm{A} / \mathrm{m}^{2}\right)$. The electric current density vector is :

$$
i=-\left(\frac{1}{r_{11}} \frac{\partial \varphi}{\partial x_{1}}, \frac{1}{r_{22}} \frac{\partial \varphi}{\partial x_{2}}, \frac{1}{r_{33}} \frac{\partial \varphi}{\partial x_{3}}\right)
$$

where $i$ is determined via the electric potential $\varphi[\mathrm{V}]$. To obtain the electric potential $\varphi$, flow simulation utilizes the steady-state Laplace equation :

$$
\frac{\partial}{\partial x_{i}}\left(\frac{1}{r_{i i}} \frac{\partial \varphi}{\partial x_{i}}\right)=0
$$

where $r_{i i}$ is the temperature-dependent electrical resistivity in the $i$-th coordinate direction. In this case, the simulation of thermal distribution on copper connection was made using Solidwork 12 for each sample. The cross-sectional of copper connection that selected is $3 \times 30 \mathrm{~mm}=90 \mathrm{~mm}^{2}$, and the contact area is $30 \times 30$ $\mathrm{mm}$. The Configuration of connections are shown in Figure 4.

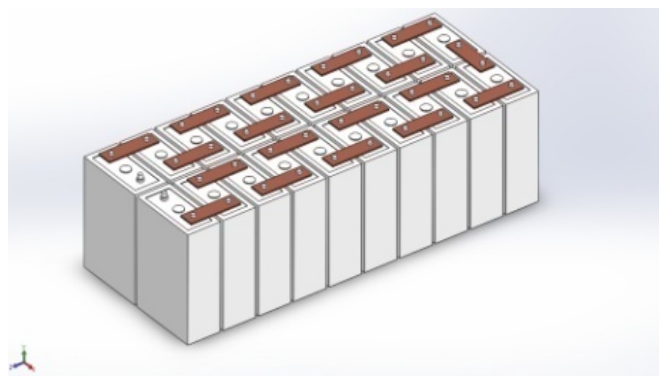

(a)

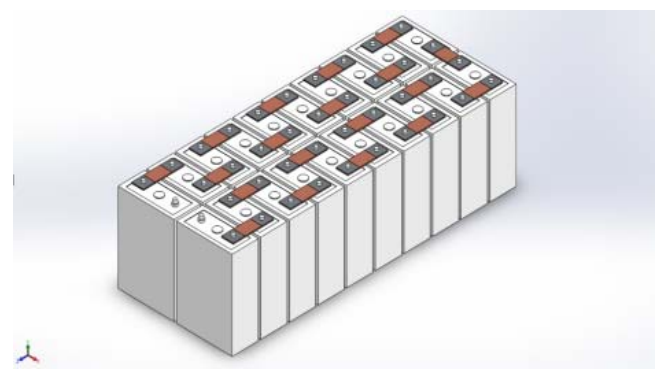

(b)

Figure 4. Configuration of connections, (a) Copper connector, and (b) Copper connector with silver coating

Parameters used in on the samples are as shown in the Table 1 as follow:

Table 1. The Input Parameters Used In The Simulation Of Thermal Flow On Connection Part

\begin{tabular}{ccccccc}
\hline No & Sampel of connection & $\begin{array}{c}R_{c} \\
(\mu \Omega)\end{array}$ & $\begin{array}{c}P \\
(\mathrm{~W})\end{array}$ & $\begin{array}{c}h \\
\left(\mathrm{~W} / \mathrm{m}^{2} \mathrm{~K}\right)\end{array}$ & $\varepsilon$ & $\begin{array}{c}T_{A} \\
\left({ }^{\circ} \mathrm{C}\right)\end{array}$ \\
\hline 1. & Connector (copper) & 15,3 & 1,87 & 15 & 0,7 & 27 \\
2. & Silver-coated connector & 6,6 & 0,81 & 15 & 0,02 & 27 \\
\hline
\end{tabular}

The contact resistance $\left(R_{c}\right)$, losses $(P)$, and ambient temperature $\left(T_{A}\right)$ are obtained from measurement result. For natural convection $(h)$ is varies between $2-25 \mathrm{~W} / \mathrm{m}^{2} \mathrm{~K}$ [22],[23], in this case $h$ values of all samples were assumed at $15 \mathrm{~W} / \mathrm{m}^{2} \mathrm{~K}$ ), and emissivity of selected materials : Cu (black oxidized) and

Experimental and Simulation Studies of Thermal Distribution on Modified Connector .... (Agus Risdiyanto) 
Ag respectively are 0.7 and 0.02 [24]. The model and material properties of each sample presented in the Table 2 as follow:

Table 2. The The Model and Material Properties of connection and part of Contact

\begin{tabular}{lll}
\hline Model & & Properties \\
\hline & Name: & Copper \\
& Model type: & Linear Elastic Isotropic \\
Thermal conductivity: & $390 \mathrm{~W} /(\mathrm{m} . \mathrm{K})$ \\
& Specific heat: & $390 \mathrm{~J} /(\mathrm{kg} . \mathrm{K})$ \\
& Mass density: & $8900 \mathrm{~kg} / \mathrm{m}^{3}$ \\
& Name: & Silver \\
& Model type: & Linear Elastic Isotropic \\
& Thermal conductivity: & $420 \mathrm{~W} /(\mathrm{m} . \mathrm{K})$ \\
& Specific heat: & $230 \mathrm{~J} /(\mathrm{kg} . \mathrm{K})$ \\
& Mass density: & $8500 \mathrm{~m}^{3}$ \\
\hline
\end{tabular}

The procedures in the simulation of thermal flow is as shown in Figure 5 below:

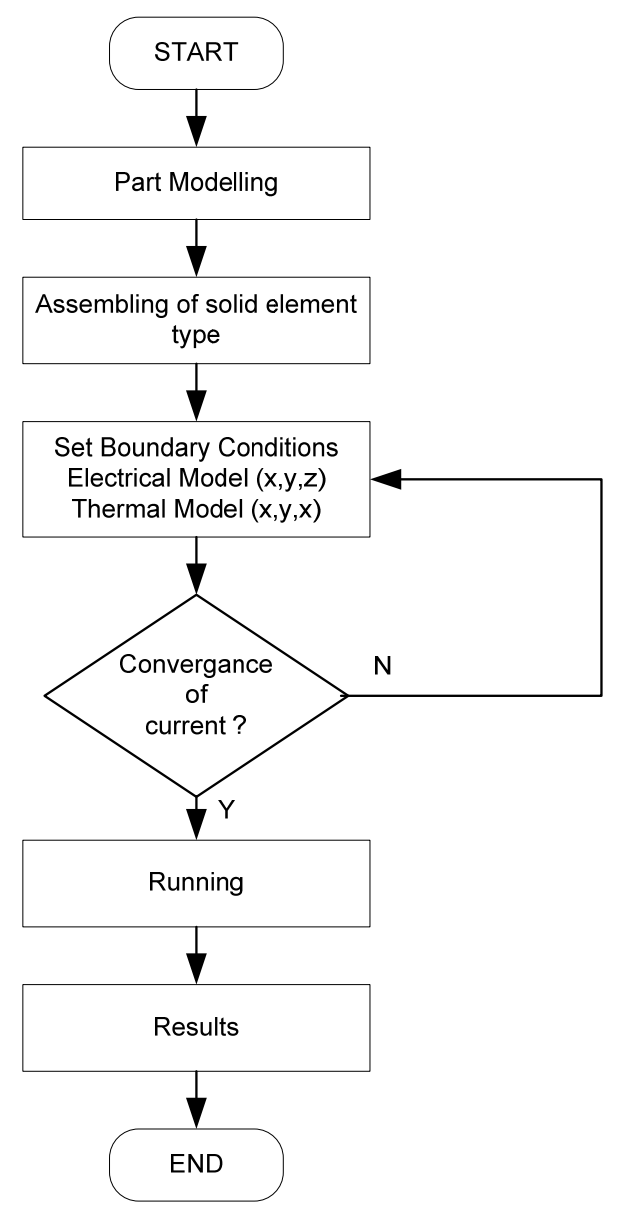

Figure 5. Flowchart of simulation

However, thermal flow simulation shows only the maximum temperature of the connections and not affected by the time of loading, thus the transient state can not be displayed. 


\section{RESULTS AND DISCUSSION}

Temperature measurements was done by loading dc constant current of 350 A until the steady state temperature reached. The changes in temperature of each connection from measurement results is as shown in Figure 6.

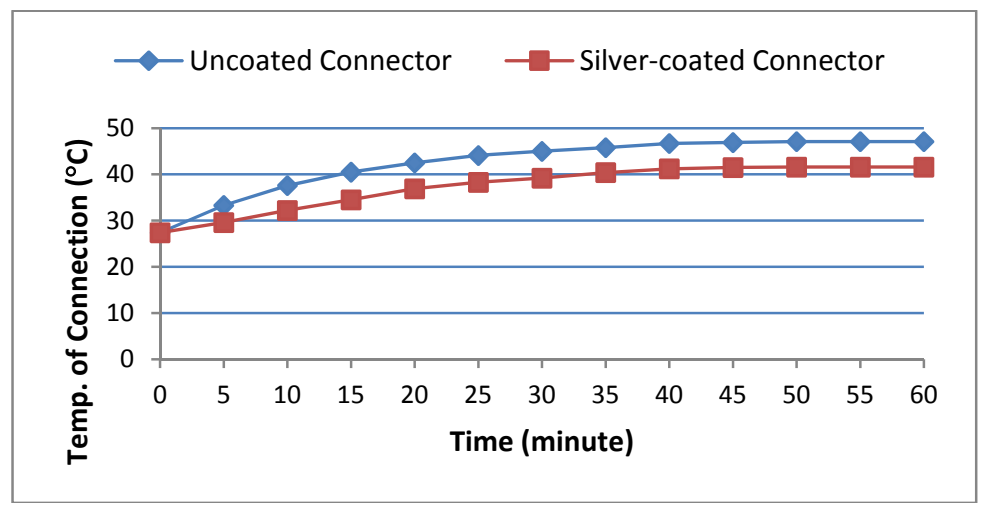

Figure 6. Temperature characteristics of the samples with the contact pressure $12 \mathrm{MPa}$ and 350A loading for 60 minutes

Copper connection with silver coating having lower maximum temperature $41.6^{\circ} \mathrm{C}$, and copper connection without coating is $47.1^{\circ} \mathrm{C}$. For both samples, temperature steady state is reached after 50 minutes of loading. Different maximum temperature of each sample occured based on different thermal coefficient, extensive real contact area (spot), others material properties like roughness and hardness.

By knowing the voltage drop at 350 A dc current load, losses on connections can be determined as well. The measurement results is shown in Figure 7 as follows:

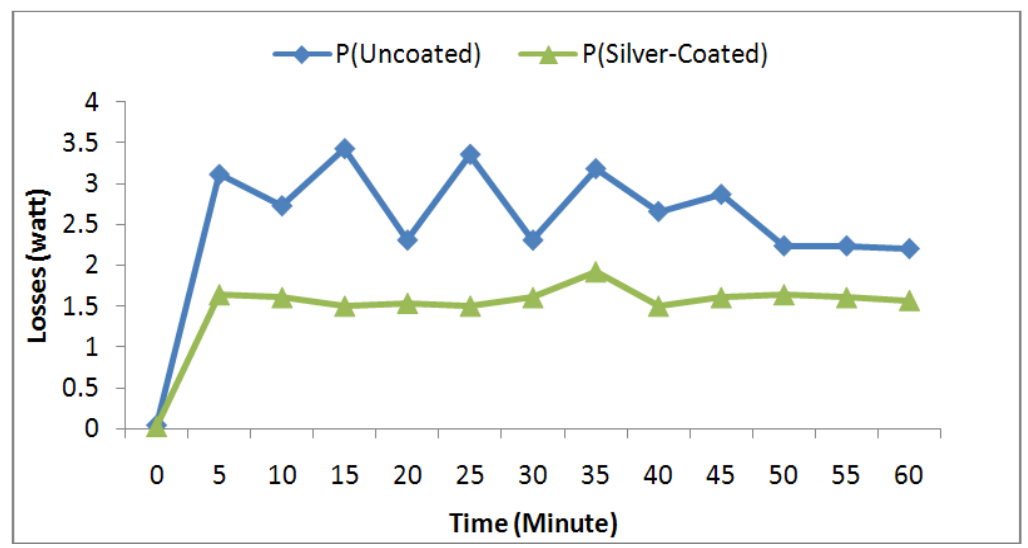

Figure 7. Power losses characteristics of the connection samples

Resistance value is influenced by temperature, and temperature changes cause changes in resistance of a material. Thus, during the rise in temperature at a relatively constant load current, the voltage drop reading at the connections will be fluctuated until stable temperature reached. The characteristics of power losses in all samples are similar to the characteristics of voltage drop. This is because the voltage drop and the power loss have a linear relationship. The fluctuations of losses in all samples above occur at the same time duration, i.e. for 50 minutes from the start of loading. This is due to the increase of temperature has not reached in a constant value. For loading by DC current, measurement results tend to be the same as the result of loading by AC current which has been published in previous papers [19] even for different applications. Refers to calculation of power loss in steady state temperature, it could be explained that copper connection with silver coating having lower losses about 32\% than copper connection without coating. It is superior compared to using configuration of bruss-copper contact that only 6\% [8]. 
In simulation, the results are shown as in Figure 8. Based on the power loss, the copper connection is divided into 3 parts, namely copper part 1, contact part, and copper part 2. For copper part 1 and copper part 2 have the same dimensions with resistance along the $270 \mathrm{~mm}$ and a load current of 350 A produces power loss of $6.6 \mathrm{~W}$. While the power loss due to contact resistance at each connection sample using equation (3) corresponding specific Joule heat $Q_{J}$ for copper connections $1.87 \mathrm{~W}$, and connection with silver coating $0.81 \mathrm{~W}$.

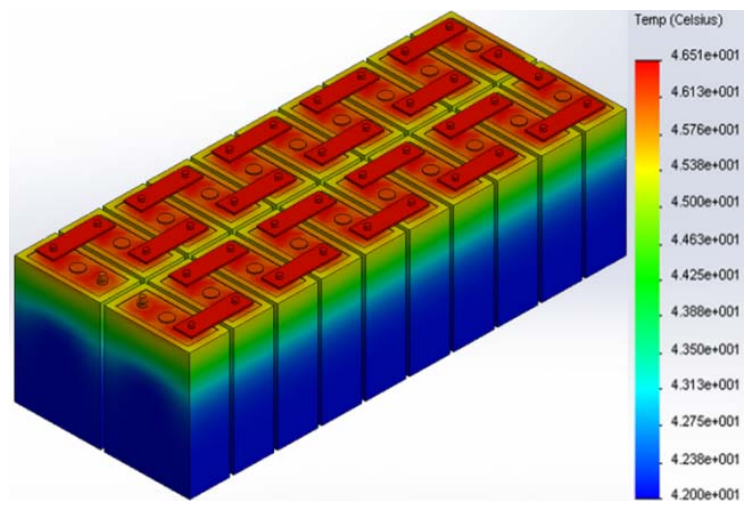

(a)

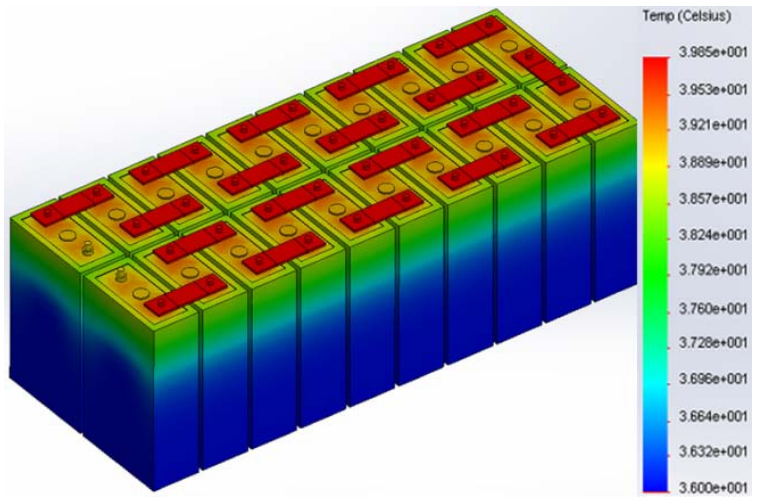

(b)

Figure 8. (a) Thermal distribution of copper connection, (b) Thermal distribution of copper connection with silver coating

The highest temperature distribution lies in the connection area, it arises because the contact resistance at the connection are a larger than outside connection, so power loss to heat generated will also be greater. Copper connections has a maximum temperature of $46.5^{\circ} \mathrm{C}$ at the contact area as shown in Figure 8(a), and copper connection with silver coating has a maximum temperature of $39.8^{\circ} \mathrm{C}$ at the contact area as shown in Figure 8(b). Comparison of temperature measurements and simulation results in the maximum temperature of each sample can be seen in the Table 3 as follow:

Table 3. Comparison Results of Maximum Temperature on Each Sample

\begin{tabular}{cccc}
\hline No & Sample of Connection & $\begin{array}{c}\text { Max. Temperature of Connection Part }\left({ }^{\circ} \mathrm{C}\right) \\
\text { (Measurement) }\end{array}$ & \begin{tabular}{c} 
(Simulation) \\
\hline 1
\end{tabular} \\
2 & Cu with Ag-coating & 47.1 & 46.5 \\
\hline
\end{tabular}

The simulation results for the maximum/steady state temperature illustrated in Figure 8 compared with the measurement results (see Figure 6) show a good agreement (slightly different). But in this case, the simulation results can not show a temperature rise based on current loading time (transient condition) as well as in the measurement results. However, simulation results can show the temperature distribution in all part of the copper, while the measurement result show the temperature only on the connection part.

Therefore, by setting the proper parameters, the application of solidwork can be considered in designing, visualizing, predicting and measuring the thermal distribution of Li-ion battery connector.

\section{CONCLUSION}

In the Li-ion battery connector, the contact area has higher thermal distribution than other areas caused by the contact resistance. Both measurement and simulation results show that copper connection with silver coating having lower maximum temperature and lower losses than copper connection without coating. Silver coating on the electrical contacts such as copper conductors with different metals can be considered to reduce the maximum temperature of the Li-ion battery connector for electrical vehicle, losses also can be reduced up to $32 \%$. Solidwork has excellent performances for designing, visualizing, and measuring the thermal distribution of Li-ion battery connector. 


\section{ACKNOWLEDGEMENTS}

The authors would like to thank to the Chairman of the Master and Doctor of Engineering Management Industry-Bandung Institute of Technology for allowing numerical simulation using Solidworks. Moreover thanks to all the team in Department of Electrical Power Engineering-School of Electrical Engineering and Informatics, Bandung Institute of Technology and The Research Centre Electrical Power and Mechatronics, Indonesian Institute of Sciences for any assistance that has been given.

\section{REFERENCES}

[1] N. Javani, et al., "Heat transfer and thermal management with PCMs in a Li-ion battery cell for electric vehicles," International Journal of Heat and Mass Transfer, vol. 72, pp. 690-703, 2014.

[2] G. H. Fofana and Y. Zhang, "Elctric Vehicle Lithium Ion Batteries Thermal Management," TELKOMNIKA Indonesian Journal of Electrical Engineering, vol/issue: 12(3), pp. 2414 - 2421, 2014.

[3] L. H. Saw, et al., "Electro-thermal analysis and integration issues of lithium ion battery for electric vehicles," Applied Energy, vol. 131, pp. 97-107, 2014.

[4] S. K. Mohammadian and Y. Zhang, "Thermal management optimization of an air-cooled Li-ion battery module using pin-fin heat sinks for hybrid electric vehicles,” Journal of Power Sources, vol. 273, pp. 431-439, 2015.

[5] G. H. Fofana and Y. Zhang, "Elctro-thermal Modeling of Lithium Ion Batteries," TELKOMNIKA Indonesian Journal of Electrical Engineering, vol/issue: 12(5), pp. 3671-3677, 2014.

[6] L. H. Saw, et al., "Integraton issues of lithium-ion battery into electric vehicles battery pack," Journal of Cleaner Production, vol. 113, pp. 1032-1045, 2016.

[7] L. Yao, et al., "Fault detection of the connection of lithium-ion power batteries based on entropy for electric vehicles,” Journal of Power Sources, vol. 293, pp. 548-561, 2015.

[8] P. Taheri, et al., "Investigating electrical contact resistance losses in lithium-ion battery assemblies for hybrid and electric vehicles,” Journal of Power Sources, vol. 196, pp. 6525-6533, 2011.

[9] M. Braunovic, "Effect of Connection Design on The Contact Resistance of High Power Overlapping Bolted Connections," IEEE Transactions CPT, vol. 8, pp. 220-229, 2001.

[10] Indonesian National Standards, "Persyaratan Umum Instalasi Listrik,” SNI 04-0225-2000, Badan Standarisasi Nasional (BSN), Jakarta, pp. 235, 2002.

[11] L. Lin, et al., "The Elctric Vehicle Lithium Battery Monitoring System,” TELKOMNIKA Indonesian Journal of Electrical Engineering, vol/issue: 11(4), pp. 2247-2252, 2013.

[12] M. Braunovic, "Reliability of Power Connections," Journal of ZhejiangUniversity SCIENCE A, ISSN 1009-3095, pp. 343-356, 2007.

[13] E. J. Graham, "Optimizing Copper To Copper Contact Performance In Marine Battery Disconnect Switches," Master of Mechanical Engineering, Rensselaer Polytechnic Institute, Troy, New York, pp. 16, 2005.

[14] Suwarno, "Material Elektroteknik," Bandung Institute of Technology, Megatama, ISBN: 979-99701-1-3, pp. 80-93, 2006.

[15] M. A. Farahat, "Factors Affecting The Life Time of The Electric Joints," Proceedings of the $14^{\text {th }}$ International Middle East Power Systems Conference (MEPCON’10), Cairo University, Egypt, pp. 163-168, 2010.

[16] M. Braunovic, at al., "Electrical Contacts Funcamentals, Applications And Techology,” CRC Press, Taylor and Francis Group, ISBN: 1-57444-727-0, pp. 73, 2006.

[17] I. Popa, at al., "Modelling and Optimization of High Currents Dismountable Contacts," International Conference on Electromechanical and Power Systems, Chisinau, Rep. Moldova, pp. 76 - 81, 2007.

[18] S. Bhattacharyya, at al., "Electrical Performance of Conductive Bolted Connections of Copper and Aluminum Busbars,” Int J Engg Techsci, vol/issue: 2(4), pp. 275-280, 2011.

[19] Suwarno, at al., "Effect of Contact Pressure and Plating Materials on Maximum Temperature, Voltage Drop, and Losses of Copper Busbar Joints," Joint International Conference on rural Information and Communication Technology and Electric Vehicle Technology, pp. 319-324, 2013.

[20] W. Parbowo and A. Purwadi, "Regenerative Braking Performance Analysis on Gang Car Electric," 2013 International Conference on Information Technology and Electrical Engineering (ICITEE), pp. 397-402, 2013.

[21] ASTM B539-02, "Standard Test Methods for Measuring Resistance of Electrical Connections (Static Contacts)," West Conshohocken, PA, 19428-2959 USA, 2008.

[22] P. M. Kurowski, “Thermal Analysis with Solidworks Sumulation 2012,” Textbooks, Schroff Development Corporation, Mission KS 66222, pp. 10, 2012.

[23] E. Rathakrishnan, "Fundamentalsof Engineering Thermodynamics," 2nd Edition, ISBN 81-203-2790-X, PrenticeHall of India, pp. 529, 2005.

[24] M. D. Griffin and J. R. French, "Space Vehicle Design,” Second Edition, American Institute of Aeronautics and Astronautics, ISBN 1-56374-539-1, pp. 635, 2005. 


\section{BIOGRAPHIES OF AUTHORS}

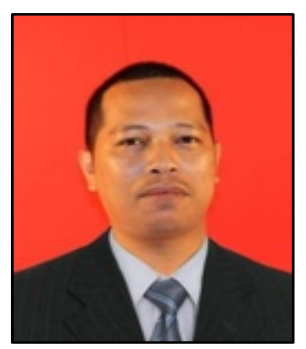

Agus Risdiyanto received Master Degrees in Electrical Enginering from School of Electrical Engineering and Informatics, Bandung Institute of Technology (ITB), Bandung, Indonesia in 2013. He has been working as a researcher in Research Center for Electric Power and Mechatronics, Indonesian Institute of Sciences (LIPI) since 2008 until now. His research areas are energy conversion, high voltage material and technology, and maintenance of high voltage apparatus.

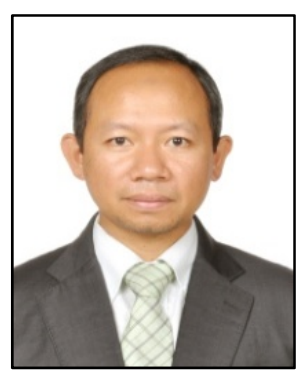

Umar Khayam received Ph.D from Kyushu Institute of Technology, Japan in 2008. He is a teacher and a researcher in Bandung Institute of Technology (ITB), Bandung, Indonesia. His field of expertises are Diagnosis of High Voltage Equipment Based on Partial Discharge Measurement; High Voltage Engineering; Transformer, Gas Insulated Switchgear and Power Cable.

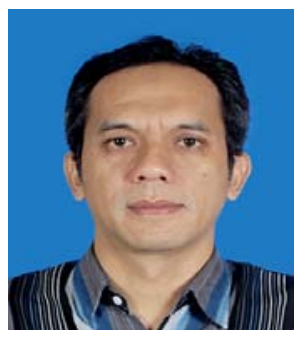

Noviadi A. Rachman received Master Degrees in Electrical Enginering from School of Electrical Engineering and Informatics, Bandung Institute of Technology (ITB), Bandung, Indonesia in 2012. He has been working as a researcher in Research Center for Electric Power and Mechatronics, Indonesian Institute of Sciences (LIPI) since 2008 until now. His research areas are electric power distribution system, power generation system, high voltage engineering.

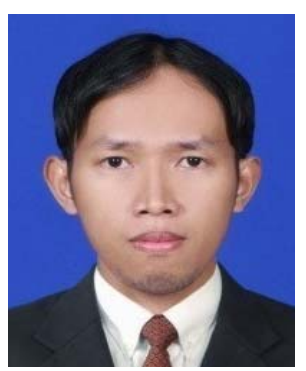

Maulana Arifin received Master Degrees in Mechanical Enginering and Aerospace Faculty, Bandung Institute of Technology (ITB), Bandung, Indonesia in 2014. He has been working as a researcher in Research Center for Electric Power and Mechatronics, Indonesian Institute of Sciences (LIPI) since 2011 until now. His research areas are Thermofluid, RG Energy Conversion and Conservation. 